\title{
FAKTOR-FAKTOR YANG MEMPENGARUPI KINERJA PEGAWA PADA PERUSAHAAN DAERAH AIR MINUM KABUPATEN ALOR
}

\author{
RAHMATLAAN
}

Abstrak: Masalah yang akan dikaji dalam penelitian ini adalah (1) Bagaimana pengaruh faktor keamanan kerja, upah/gaji dan kesempatan untuk maju, terhadap kinerja Pegawai pada PDAM Kabupaten Alor, (2) Diantara faktor-faktor tersebut mana yang mempunyai pengaruh paling dominan terhadap kinerja Pegawai pada PDAM Kabupaten Alor. Tujuan yang ingin dicapai dalam penelitian ini adalah (1) Untuk mengetahui bagaimana pengaruh faktor keamanan kerja, upah/gaji dan kesempatan untuk maju terhadap kinerja Pegawai pada PDAM Kabupaten Alor, (2) Untuk mengetahui diantara faktor-faktor tersebut mana yang mempunyai pengaruh paling dominan terhadap kinerja Pegawai pada PDAM Kabupaten Alor. Dari segi metodelogi, penelitian ini bersifat studi kasus. Data penelitan bersumber primer, dengan teknik pengumpulan data adalah angket. Jenis data kualitatif yang dikuantifikasi dengan Skala Likert. Sampel penelitian sebanyak 33 arang. Sedangkan analisis data menggunakan regresi berganda dengan formula: $Y=a+b 1 X 1+b 2 X 2+b 3 X 3$. Hasil penelitian menunjukkan bahwa (1) Secaia simultan (bersama-sama) keamanan kerja, upah/gaji, dan kesempatan untuk maju berpengaruh signifikan terhadap kinerja Pegawai pada PDAM Kabupaten Alor. Hal ini terbukti dimana $F$ hitung lebih besar dari $F$ tabel dan siginifikan $F<0,05$ ( $F h=644,6442>F$ tabel $=2,93$ dan siginifikan $F=0,000<0,05$ ). Sedangkan besarnya pengaruh keamanan kerja, upah gaji, dan kesempatan untuk maju terhadap kinerja Pegawai pada PDAM Kabupaten Alor adalah $98,5 \%$ (2) Secara parsial (sendiri-sendiri) keamanan kerja berpengaruh signifikan terhadap kinerja Pegawai pada PDAM Kabupaten Alor. Hal ini terbukti dimana thitung untuk variable keamanan kerja lebih besar dari t tabel dan siginikan $t<0,05$ ( $t$ hitung $=2,226>t$ tabel $=1,697$ dan signifikan $t=0,034<0,05$ ) (3) Secara parsial (sendiri-sendiri) upah/gaji berpengaruh signifikan terhadap kinerja Pegawai pada PDAM Kabupaten Alor. Buktinya thitung untuk variable upah/gaji lebih besar dari t tabel dan signifakan $t<0,05$ (t hitung $=4,781>$ tabel $=1,697$ dan signifikan $t=0.000$ $<0,05)$ (4) Secara parsial (sendiri-sendiri) kesempatan untuk maju berpenganh signifikan terhadap kinerja Pegawai pada PDAM Kabupaten Alor. Buktinya thitung untuk variable kesempatan untuk maju lebih besar dari $t$ tabel dan signifakan $t<0,05$ ( $t$ hitung $=3,368>t$ tabel $=1,697$ dan signifikan $t=0,002<0,05$ ) (5) Upah/gaji mempunyai pengaruh paling dominan terhadap kinerja pegawai pada PDAM Kabupaten Alor: Hal ini karena koefisien regresinya =1,222 lebih besar dari koefisien regresi variabel lainnya. Dari hasil penelitian ini maka kepada PDAM Kabipaten Alor disarankan untuk memperhatikan:

(1) Keamanan dalam bekerja bagi para pegawai, (2) Upah/gaji juga hendaknya disesuaikan dengan besarnya tugas dan tanggung jawab yang diberikan, (3) Kesempatan untuk maju hendaknya disedikan kepada para pegawai yang ingin melanjutkan ke jenjang pendidikan yang lebih tinggi. Denikian juga kesempatan untuk mengikuti kursus-kursus atau pelatihan-pelatihan dalam rangka peningkatan keterampilan dalam bekerja.

Kata Kanci : Kinerja, Keamanan kerja, Upah/gaji, Kesemapatan uniuk maju

Rahmat, Adalah Dosen Fakultas Ehonomi Univ. Muhammadiyah Kupang 


\section{PENDAHULUAN}

Dewasa ini salah satu topik yang selalu aktual diwacanakan, baik oleh masyarakat awam maupun para pakar manajemen sumber daya manusia adalah kinerja organisasi. Kinerja organisasi menjadi topik yang demikian urgen, karena hal ini sangat menentukan eksistensi sebuah organisasi, baik yang berorientasi laba (bisnis) maupun nir laba (publik).

Salah satu factor yang menentukan kinerja organisasi adalah kinerja pegawainya. Kinerja organisasi dan kinerja pegawai berkorelasi positif. Semakin tinggi kinerja pegawai akan semakin tinggi pula kinerja organisasi, sebaliknya semakin rendah kinerja pegawai akan semakin rendah pula kinerja organisasi. Oleh karena itu, untuk meningkatkan kinerja organisasi, perhatian terhadap kinerja pegawai menjadi sebuah keniscayaan.

Kinerja pegawai, menurut Gomes (1995: 195) dipersamakan dengan ungkapan seperti output, efisiensi serta efektivitas dan sering dihubungkan dengan produktivitas. Sedangkan kinerja pegawai menurut Mangkunegara (2000: 67) adalah hasil kerja secara kualitas dan kuantitas yang dicapai oleh seorang karyawan dalam melaksanakan tugasnya sesuai dengan tanggung jawab yang diberikan kepadanya.

Menurut T.R. Mitchell (1999 : 73) baik tidaknya kinerja seorang pegawai dapat dilihat dari quality of work (kualitas kerja), promptnees (ketepatan waktu), initiative (inisiatif), capability (kemampuan) dan communication (komunikasi). Apabila ktriteria-kriteria di atas dapat diwujudkan secara baik, maka seorang pegawai dapat dikataKan mempunyai kinerja yang baik dan seballknya apabila tidak terwujud maka kinerja seorang pegawai/karyawan dikatakan kurang baik.

Mewujudkan kinerja (hasil kerja) pegawai yang baik bukan perkara yang mudah. Hal ini karena kinerja pegawai dipengaruhi cleh beragam varabel. Stephen P. Robbins (1996), berpendapat bahwa kinerja seorang karyawan dipengaruhi oleh faktor-faktor : tipe kerja, rekan sekerja, tunjangan, diperlakukan dengan hormat dan adil, keamanan kerja, peluang menyumbangkan gagasan, upah/gaji, pengakuan akan kinerja, kesempatan untuk maju dan sebagainya.

Sementara itu Sedarmayanti (2001) membagi faktor-faktor yang mempegaruhi kinerja pegawai sebagai berikut (1) faktor organisasi, (2) faktor individu dan (3) faktor sosial. Faktor organisasi terbagi dalam (1) selama bekerja yaitu keterlambatan, kehadiran, pelatihan, penurunan produktifitas, perombakan rencana/jadwal, peningkatan tanggung jawab kepengawasan, kekeliruan dan ketidak efisienan. Ke (2) di luar pekerjaan yang meliputi kehilangan investasi, semangat, rekruitmen, seleksi dan penempatan, kekurangan biaya, dan kompensasi yang sebenanya. Faktor individu meliputi pengaruh karir, pengaruh kemampuan, pengaruh sosial, pengaruh keluarga dan pengaruh psikologis. Sedangkan faktor sosial mencakup ketidak puasan klien, hubungan masyarakat, kredibilitas dan kapabilitas system untuk memberikan pelayanan efektif, kekurangan dalam hal kualitas pelayanan pendidikan dan kegagalan memperoleh hasil sesuai standar.

Hasil pengamatan menunjukkan bahwa kinerja pegawai pada PDAM Kabupaten Alor belum terwujud seperti apa yang diharapkan. Hal ini disebabkan oleh beragam factor di atas. Namun pada penelitian ini, dibatasi pada factor keamanan kerja, upah/gaji dan kesempatan untuk maju.

Bertolak dari uraian di atas, maka masalah pokok dalam penelitian ini dapat dinumuskan sebagai berikut: (1) Bagaimana pengaruh faktor keamanan kerja, upah/gaji dan kesempatan untuk maju secara simultan, terhadap kinerja Pegawai pada PDAM Kabupaten Alor, (2) Bagaimana pengaruh faktor keamanan kerja, upah/gaji dan kesempatan untuk maju secara parsial, terhadap kinerja Pegawai pada PDAM Kabupaten Alor, (3) Diantara faktor-faktor tersebut mana yang mempunyai pengaruh paling dominan terhadap kinerja Pegawai pada PDAM Kabupaten Alor.

Tujuan yang hendak dicapai dalam penelitian ini adalah (1) Untuk mengetahui bagaimana 
wh faktor keamanan kerja, upah/gaji dan satan untuk maju secara simultan, tch adap Pegawai pada PDAM Kabupaten Alor, (2) mengetahui bagaimana pengaruh faktor nan kerja, upah/gaji dankesempatan untuk secara parsial, terhadap kinerja Pegawai DAM Kabupaten Alor, (3) Untuk mengetazntara faktor-faktor tersebut manakah yang unyai pengaruh paling dominan.

idapun manfaat dari penelitian ini yaitu; aplaan penelitian ini menjadi bahan informasi .2 rangka pengambilan kebijakan menyangnerja pegawai pada PDAM Kabupaten Alor. aping itu sebagai bahan rujukan bagi pihak yang berkeinginan untuk melakukan litian lanjutan.

\section{otesis}

Dari permasalahan yang dirumuskan sebenya, maka model hipotesis dalam penelitian apat digambarkan seperti tampak dibawah ini.

$$
\begin{gathered}
\text { Gambar } 1 \\
\text { Model Hipotesis }
\end{gathered}
$$

Faktor-Faktor Berpengaruh (X)

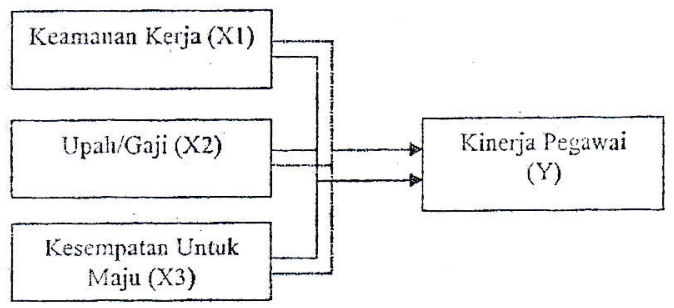

Keterangan:

Pengaruh Simultan : Pengaruh Parsial:

Berdasarkan gambar di atas, maka hipotesis apat dirumuskan sebagai berikut:

Di duga faktor keamanan kerja, upah/gaji dan kesempatan untuk maju secara simultan berpengaruh signifikan terhadap kinerja Pegawai pada PDAM Kabupaten Alor.

$\therefore$ Di duga keamanan kerja, upah/gaji dan kescmpatan untuk maju secara parsial berpengaruh signifikan terhadap kinerja Pegawai pada PDAM Kabupaten Alor.
3. Di duga faktor upak/gaji berpengaruh lebih cominan terhadap kinerja Pegawai pada PDAM Kabupaten Alor.

\section{METODE PENELITIN}

Sumber data adalah data primer, jenis data bersifat kualitatif dan dikuantifikasi dengan skala Likert. Teknik pengumpulan data yang digunakan adalah angket. Sampel penelitian sebanyak 33 orang. Teknik analisis data meggunakan regresi berganda dengan formula: $\mathrm{Y}=\mathrm{a}+\mathrm{b} 1 \mathrm{X} 1+\mathrm{b} 2 \times 2$ + b3X3, dimana:

$\mathrm{Y}=$ Kinerja pegawai

$a=$ Konstanta

b1-b3 = Koefisien regresi

$\mathrm{X} 1$ = Keamanan kerja

$\mathrm{X} 2=\mathrm{Upah} / \mathrm{Gaji}$

$\mathrm{X} 3$ = Kesempatan untuk maju

Untuk pembuktian hipotesis akan dipergunakan uji $F$ dan uji $t$ sebagai berikut:

\section{UjiF}

Uji $\mathrm{F}$ dipergunakan untuk menjelaskan pengaruh variable keamanan kerja, upah/gaji dan kesempatan untuk maju secara simultan terhadap variable kinerja pegawai. Uji ini ditujukan untuk pembuktian hipotesis no 1. Formula yang dipergunakan adalah :

$$
\text { Fh } \frac{R^{2} / k}{\left(1-R^{2}\right) /(n-k-1)} \text { (Sugiyono, } 2004: 190 \text { ) }
$$

Kaidah yang dipergunakan dalam uji $\mathrm{F}$ adalah:

- Jika F hitung lebih besar dari F table atau signifikansi $F$ lebih kecil 5\% (alfa yang digunakan), berarti variable keamanan kerja, upah/gaji dan kesempatan untuk maju secara simultan berpengaruh signifikan terhadap variable kinerja pegawai.

- Jika F hitung lebih kecil dari F table atau signifikansi $\mathrm{F}$ lebih besar 5\% (alfa yang digunakan), berarti variable keamanan kerja, upah/gaji dan kesempatan untuk maju secara simultan tidak berpengaruh signifikan terhadap variable kinerja pegawai. 


\section{Ujit}

Uji $\mathbf{t}$ dipergunakan untuk menjelaskan pengaruh variable keamanan kerja, upah/gaji dan kesempatan untuk maju secara parsial terhadap variable kinerja pegawai. Uji ini ditujukan untuk pembuktian hipotesis no 2. Formula yang digunakan adalah:

$$
t h=\frac{b-\beta}{S b}
$$

Kaidah yang digunakan dalam uji t adalah :

- Jika $t$ hitung lebih besar dari t table atau signifikansi t lebih kecil 5\% (alfa yang digunakan), berarti variable keamanan kerja, upah/gaji dan kesempatan untuk maju secara parsial berpengaruh signifikan terhadap variable kinerja pegawai.

- Jika thitung lebih kecil dari t table atau signifikansi t lebih besar 5\% (alfa yang digunakan), berarti variable keamanan kerja, upal/gaji dan kesempatan untuk maju secara parsial tidak berpengaruh signifikan terhadap variable kinerja pegawai.

\section{HASI DAN PEMBAHASAN}

Data yang dipergunakan untuk analisis adalah data-data jawaban responden terhadap angket yang disebarkan. Daia-data tersebut kemudian diskoring dengan menggunakan skala Likert dengan klasifikasi 5 sangat setuju, 4 setuju, 3 netral/tidak berpendapat, 2 tidak setuju dan 1 sangat tidak setuju.

Setelah diskoring, selanjutnya diproses dengan bantuan program SPSS versi 11. Adapun ringkasan hasil proses data tersebut dapat disimak pada table berikut :

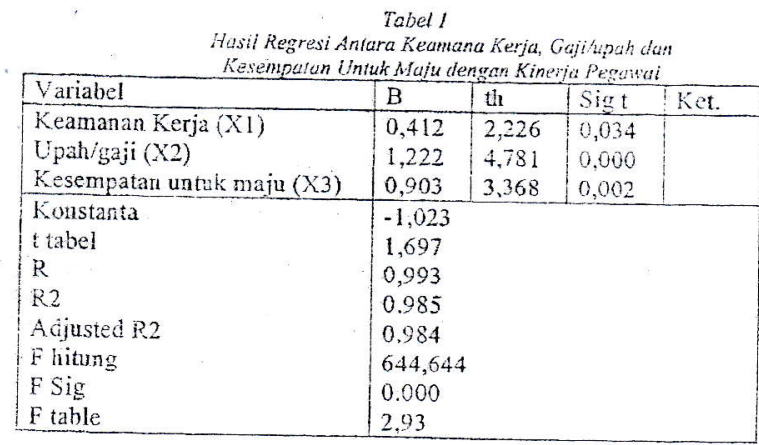

a. Persamaan Regresi Berganda

Persamaan regresi berganda yang dihasilkan dari proses perhitungan sebagaimana pada tabel di atas adalah sebagai beriku: $\mathrm{Y}=-1,023+0,412 \mathrm{X} 1+1,222 \times 2+$ $0,903 \times 3$. Makna dari persamaan regresi ini dapat dijelaskan sebagai berikut :

- Jika keamanan kerja, upah/gaji dan kesempatan untuk maju dalam keadaan konstan (tidak berubah) maka kinerja pegawai PDAM sama dengan $-1,023$.

- Jika keamanan kerja ditingkatkan sebesar 1, maka kinerja pegawai PDAM akan meningkat sebesar 0,412 .

- Jika upah/gaji ditingkatkan sebesar 1, maka kinerja pegawai PDAM akan meningkat sebesar 1,222.

- Jika kesempatan untuk maju ditingkatkan sebesar 1, maka kinerja pegawai PDAM akan meningkat sebesar 0,903 .

b. Uji Hipotesis

1) Uji F (Uji Simultan)

Uji F dimaksudkan untuk mengetahui pengaruh variabel keamanan kerja, upah/ gaji, dan kesempatan untuk maju secara bersama-sama terhadap variabel kinerja pegawai. Apabila hasil pengujian menunjukkan signifikansi ( $\mathrm{F}$ hitung $>\mathrm{F}$ tabel atau signifikansi $\mathrm{F}<5 \%$ ), maka dapat disimpulkan bahwa variabel keamanan kerja, upah/gaji, dan kesempatan untuk maju secara bersama-sama berpengaruh signifikan terhadap variabel kinerja pegawai. Bila hasilnya tidak, maka variabel keamanan kerja, upah/gaji, dan kesempatan untuk maju secara bersama-sama tidak berpengaruh signifikan terhadap variabel kinerja pegawai.

Dari hasil pengujian sebagaimana pada tabel 6 di atas diperoleh $\mathrm{F}$ hitung sebesar 644,644 dengan signifikansi $F$ sebesar 0,000. Nilai F tabel sebesar 2,93, sehingga terlihat bahwa $\mathrm{F}$ hitung $>\mathrm{F}$ tabel dan signifikansi $F<0.05$. Artinya secara 


(1)

bersama-sama (simultan) variabel keamanan kerja, upah/gaji, dan kesempatan untuk maju berpengaruh signifikan terhadap variabel kinerja pegawai. Dengan demikian maka hipotesis no 1 yang dibangun terbukti.

Dari tabel di atas juga diperoleh $\mathrm{R}$ Square atau koefisien determinasi sebesar 0,985 atau $98,5 \%$. Artinya bahwa kinerja pegawai dapat dijelaskan oleh variabel keamanan kerja, upah/gaji, dan kesempatan untuk maju sebesar $98,5 \%$, sedangkan sisanya sebesar $1,5 \%$ dijelaskan oleh variabel lain di luar variabel yang diteliti.

2) Ujit (Uji Parsial)

Uji t dimaksudkan urituk mengetahui pengaruh variabel keamanan kerja, upah/ gaji, dan kesempatan untuk maju secara sendiri-sendiri (parsial) terhadap variabel kinerja pegawai. Bila hasil pengujian $t$ adaiah signifikan ( $\mathrm{t}$ hitung $>\mathrm{t}$ tabel dan signifikansit $<5 \%$ ) maka dapat dikatakan bahwa variabel keamanan kerja, upah/gaji, dan kesempatan untuk maju secara parsial berpengaruh signifikan terhadap variabel kinerja pegawai. Sebaliknya jika dari hasil pengujian diperoleh angka yang tidak signifikan, maka dapat dikatakan variabel keamanan kerja, upah/gaji, dan kesempatan untuk maju secara parsial tidak berpenganuh secara signifikan terhadap variabel kinerja pegawai.

a. Keamanan Kerja (X1)

Dari tabel di atas, variabel keamanan kerja mempunyai t hitung sebesar 2,226 dengan signifikan $\mathrm{t}$ sebsar $0,034, \mathrm{t}$ tabel sebesar 1,697. Karena t hitung $>t$ tabel dan signifikan $t<0,05$, maka secara parsial variabel keamanan kerja $(\mathrm{X} 1)$ berpengaruh signifikan terhadap kinerja pegawai (Y), bila variabel lain konstan.

b. Upah/gaji (X2)

Dari tabel di atas, variabel upah/gaji mempunyai thitung sebesar 4,781 dengan signifikan $t$ sebesar $0,000, t$ tabel sebesar
1,697. Karena t hitung $>\mathrm{t}$ tabel dan siginifikan $\mathrm{t}<0,05$, maka secara parsial variabel upah/gaji (X2) berpengaruh signifikan terhadap kinerja pegawai (Y), bila variabel lain konstan.

c. Kesempatan untuk maju (X3)

Dari tabel di atas, variabel kesempatan untuk maju mempunyai thitung sebesar 3,368 dengan signifikan t sebesar 0,002, $\mathrm{t}$ tabel sebesar 1,697. Karena thitung $>\mathrm{t}$ tabel dan siginifikan $t<0,05$, maka secara parsial variabel kesempatan untuk maju (X3) berpengaruh signifikan ternadap variabel kerja pegawai (Y), bila variabel lain konstan.

Dari hasil uji parsial tersebut, terlihat bahwa hipotesis no 2 juga terbukti.

d. Dari ketiga variabel bebas yang dianalisis terbukti bahwa variabel upah/gaji mempunyai pengaruh paling dominan terhadap variabel kinerja pegawai pada PDAM Kabupaten Alor. Hal ini terlihat dari koefisien regresi dimana variabel upah/gaji mempunyai koefisien regresi sebesar 1,222 lebih besar dari variabel lainnya. Dengan demikian hipotesis no 3 juga terbukti.

\section{KESIMPULANDAN SARAN \\ Kesimpulan}

Bertolak dari hasil analisis sebagaimana diuraikan di atas, berikut akan disimpulkan beberapa hal sebagai berikut :

1. Secara simultan (bersama-sama) keamanan kerja, upah/gaji, dan kesempatán untuk maju berpengaruh signifikan terhadap kinerja Pegawai pada PDAM Kabupaten Alor. Hal ini terbukti dimana $F$ hitung lebih besar dari $F$ tabel dan siginifikan $\mathrm{F}<0,05 .(\mathrm{Fh}=644,6442$ $>\mathrm{F}$ tabel $=2,93$ dan siginifikan $\mathrm{F}=0,000<$ $0,05)$. Sedangkan besarnya pengaruh keamanan kerja, upah/gaji, dan kesempatan untuk maju terhadap kinerja Pegawai pada PDAM Kabupaten Alor adalah 98,5\%.

2. Secara parsial (sendiri-sendiri) keamanan 
kerja berpengaruh signifikan terhadap kinerja Pegawai pada PDAM Kabupaten Alor. Hasil penelitian menunjukkan bahwa thitung lebih besar dari t tabel dan siginikan $\mathrm{t}<0,05$ ( $\mathrm{t}$ hitung $=2,226>t$ tabel $=1,697$ dan signifikan $t=0,034<0,05)$.

3. Secara parsial (sendiri-sendiri) upah/gaji berpengaruh signifikan terhadap kinerjaa Pegawai pada PDAM Kabupaten Alor. Buktinya thitung lebih besar dari t tabel dan signifakan $t<0,05$ ( $t$ hitung $=4,781>t$ tabel $=1,697$ dan signifikan $t=0.000<0,05)$.

4. Secara parsial (sendiri-sendiri) kesempatan untuk maju berpengaruh signifikan terhadap kinerja Pegawai pada PDAM Kabupaten Alor. Buktinya thitung lebih besar dari tabel dan signifakan $t<0,05$ ( $t$ hitung $=3,368>\mathrm{t}$ tabel $=1,697$ dan signifikan $\mathbf{t}=0,002<0,05$ ).

5. Upah/gaji mempunyai pengaruh paling dominan terhadap kinerja pegawai pada PDAM Kabupaten Alor. Hal ini karena koefisien regresinya $=1,222$ lebih besar dari variabel lainnya.

Saran

Mencermati hasil penelitian sebagaimana disimpulkan di atas, maka kepada PDAM Kabupaten Alor disarankan untuk memperhatikan beberapa hal sebagai berikut:

1. Keamanan kerja berpengaruh signifikan terhadap kinerja Pegawai pada PDAM Kabupaten Alor. Oleh karena itu keamanan dalam bekerja bagi para pegawai hendaknya diperhatikan terutama menyanagkut kemanan selama bekerja atau melaksanakan tugas.

2. Upah/gaji berpengaruh signifikan terhadap kinerja Pegawai pada PDAM Kabupaten Alor. Oleh karena itu upah/gaji juga hendaknya diperhatikan untuk disesuaikan dengan besarnya tugas dan tanggung jawab yang diberikan.

3. Kesempatan untuk maju berpengaruh signifikan terhadap kinerja Pegawai pada PDAM Kabupaten Alor. Oleh karena itu kesempatan wtuk maju hendaknya disedikan kepada para pegawai yang ingin melanjutkan ke jenjang pendidikan yang lebih tinggi. Demikian juga tatsing

kesempatan untuk mengikuti kursus-kursus atau pelatihan-pelatihan agar disediakan kepada para pegawai untuk meningkatan keterampilan mereka dalam bekerjà.

\section{DAFTAR PUSTAKA}

atros

Anonimous, 1996, Perilaku Organisasi, Konsep

Kontroversi-Aplikasi, jilid I Edisi Bahasa Indonesia, Prenhalindo, Jakartá.

Anonimous, 1996, Perilaku Organisasi, Struktur, Desain dan Aplikasi, jilid 2 Prenhalindo, Jakarta.

Anonimous, 1997, Manajemen Sumber Daya Manusia, Edisi Bahasa Indoensia Jilid II, PT Prenhallindo, Jakarta.

Faustino Cardoso Gomes, 1997, Manajemen Sumber Daya Manusia, Cetakan Kedua, Penerbit Andi Ofset Yogyakarta.

Gery Dessler, 1997, Manajemen Sumber Daya

Manusia, Edisi Bahasa Indoensia Jilid I, PT Prenhallindo, Jakarta.

Hani Handoko, 1987, Manajemen Personalia dan Sumber Daya Manusia, BPFE Yogyakarta.

Heidjrachman \& Suad Husnan, 1995, Manajemen Personalia Edisi 4, BPFE Yogyakarta.

Malayu Hasibuan, 2001, Manajemen Sumber Daya Manusia, Edisi Revisi, Bumi Aksara Jakarta.

Peorwa Darminta, 1986, Kamus Unum Bahasa Indonesia, Balai Pustaka Jakarta.

Robbins Stephen P, 1995, Teori Organisasi, Struktur Desain dan Aplikasi, Alih BahasaYusuf udaya, Arcan Jakarta.

Sumhudi Aslam M, 1986, Komposisi Disain Riset, Cetakan Ketiga Penerbit CV. Ramadhani, Jakarta.

Soegeng Prijoddarminto, 1994, Disiplin Kiat Menuju Sukses, Cetakan ke 4, PT Pradnya Paramita Jakarta.

Sedarmayanti, 2001, Sumber Daya Manusia Dan Pioduktifitas Kerja, CV Mandar Maju Bandung.

Susilo Martoyo, 2000, Manajemen Sumber Daya Manusia, Edisi Ke 4, BPFE Yogyakarta 